\title{
CARACTERIZAÇÃO GEOMORFOLÓGICA DA REGIÃO CÁRSTICA ARCOS-PAINS E DE SEUS SISTEMAS CÁRSTICOS ${ }^{1}$
}

\author{
GEOMORPHOLOGICAL CHARACTERISATION OF THE ARCOS-PAINS KARST \\ REGION AND ITS KARST SYSTEMS
}

\author{
Mariana Barbosa Timo \\ Doutora em Carstologia e Doutora em Geografia \\ Engenheira Ambiental, Spelayon Consultoria, Brasil \\ mariana.timo@gmail.com
}

\section{Resumo}

A região do Grupo Bambuí, conhecida como Província Espeleológica do Bambuí (PEB), ocupa uma área de aproximadamente $150.000 \mathrm{~km}^{2} \mathrm{e}$ abrange as porções centro oeste, norte e noroeste de Minas Gerais; leste do Distrito Federal; nordeste de Goiás; sudeste do Tocantins; e oeste da Bahia. Devido à grande área ocupada pela Província Espeleológica do Bambuí, esta pode ser dividida em distritos. O objetivo deste artigo é a caracterização da Região Cárstica de Arcos-Pains, e de seus sistemas cársticos correlatos, a partir da utilização de dados geológicos, geomorfológicos, espeleológicos e hidrográficos. O carste regional é bem evoluído, com extensos maciços calcários marcados por diferentes tipos de lapiás (karren). Além disso, apresenta drenagem predominantemente subterrânea com a presença de sumidouros, ressurgências, cânions, dolinas e feições residuais, comuns na paisagem cárstica. Estruturas geológicas marcantes, como dobras e falhas, também se fazem presentes. Por outro lado, as atividades humanas podem impor profundas modificações na paisagem desta importante região cárstica, especialmente por causa da mineração, visto que ali encontram-se instaladas diversas empresas de extração de calcário, além de indústrias cimenteiras e de produção de cal. Tal uso do solo, aliado à precária gestão do Patrimônio Espeleológico, vem ocasionado impactos ambientais significativos no carste regional. Dessa forma, ter como base os estudos do carste faz-se extremamente necessário, pois a sensibilidade dos aquíferos cársticos à poluição é muito alta.

Palavras-chave: Região Cárstica Arcos-Pains, Carste, Espeleologia.

\footnotetext{
${ }^{1}$ Artigo baseado na palestra da autora no $19^{\circ}$ SEMINÁRIO CLÁUDIO PERES DE PRÁTICAS DE ENSINO E GEOGRAFIA APLICADA - GEOPATRIMÔNIO: CONEXÕES INTERDISCIPLINARES, da PUC Minas
} 


\section{Abstract}

The Bambuí Group region, known as the Bambuí Speleological Province (PEB), occupies an area of approximately $150,000 \mathrm{~km}^{2}$ and encompasses the central west, north and northwest portions of Minas Gerais; east of the Federal District; northeast of Goiás; southeast of Tocantins; and west of Bahia. Due to the large area occupied by the Speleological Province of Bambuí, it can be divided into districts. This article characterises the Arcos-Pains Karst Region and its related karst systems, using geological, geomorphological, speleological and hydrographic data. The regional karst is well developed, with extensive limestone massifs marked by different types of lapiás (karren). In addition, it has predominantly underground drainage with the presence of sinkholes, upwellings, canyons, sinkholes and residual features, common in the karst landscape. Marked geological structures, such as folds and faults, are also present. On the other hand, human activities can impose profound changes in the landscape of this important karst region, especially because of quarrying, since several companies extract limestone, as well as cement and lime production industries. Such land use, combined with the precarious management of the Speleological Heritage, has caused significant environmental impacts on regional karst. Thus, based on karst studies is extremely necessary, as the sensitivity of karst aquifers to pollution is very high.

Keywords: Arcos-Pains Karst Region, Karst, Speleology.

\section{INTRODUÇÃO}

Segundo Karmann (1994) as áreas consideradas cársticas no território nacional cobrem entre 425.000 e $600.000 \mathrm{~km} 2$, o que corresponde a aproximadamente $7 \%$ da área do país. A partir do aumento da demanda para a análise de processos de licenciamento ambiental de atividades potencialmente degradadoras e poluidoras em ambientes cársticos, surgiu a necessidade de geoespacializar os dados existentes do Patrimônio Espeleológico Brasileiro com o objetivo de promover uma melhor gestão e subsidiar a tomada de decisão (CECAV, 2011).

De acordo com Bueno e Travassos (2012), a análise de todo espaço geográfico e de todos os elementos e processos que agem nesse espaço, só é possível quando é estabelecido um sistema de escalas de grandeza. Para os autores, é necessário colocá-los em escalas de grandezas para se estabelecer comparações entre formas e sistemas de interação.

A primeira classificação do carste brasileiro foi proposta em 1979 por Karmann e Sánchez. Neste trabalho os autores descreveram os principais tipos de rochas carbonáticas existentes no território nacional e definiram cinco províncias 


\section{ORIGINAL ARTICLE}

espeleológicas: 1) Vale do Ribeira (SP), 2) Bambuí (BA, GO e MG), 3) Serra da Bodoquena (MS), 4) Alto Rio Paraguai (MT) e 5) Chapada de Ibiapaba (CE). Além destas, os autores identificaram outras nove regiões com presença de fenômenos cársticos incipientes. Vale dizer que esta classificação considerava apenas as rochas carbonáticas.

Em 1986, com o avanço das pesquisas sobre o tema, as províncias Rio Pardo (BA), Serra Geral (PR) e Alto Urubu (AM) foram incluídas nessa classificação (KARMANN; SÁNCHEZ, 1986). Destaca-se que as duas últimas províncias se desenvolvem em rochas areníticas, atualmente aceitas como sendo favoráveis ao desenvolvimento de um sistema cárstico, ainda que a dissolução não seja o fator predominante para o seu desenvolvimento, como no carste em carbonatos, e tenham suas particularidades.

Posteriormente, Auler, Rubbioli e Brandi (2001) atualizaram as classificações propostas por Karmann e Sánchez $(1979 ; 1986)$ e caracterizaram geologicamente a distribuição de 14 áreas cársticas no Brasil, com base no mapa geológico elaborado por Schobbenhaus et al. (1981). Neste trabalho os autores adotaram a terminologia "região cárstica" para designar áreas com potencialidade de ocorrência de cavernas (JANSEN; CAVALCANTI; LAMBLÉM, 2012), independente da litologia na qual as cavidades estivessem inseridas. De acordo com estes autores, em 2005, analistas ambientais do Centro Nacional de Pesquisa e Conservação de Cavernas (CECAV) iniciaram o desenvolvimento de uma metodologia para mapear áreas do território brasileiro favoráveis à ocorrência de cavernas, o que resultou na elaboração do "Mapa de Potencialidade de Ocorrência de Cavernas", publicado pela primeira vez em 2009. As pesquisas para a delimitação do Patrimônio Espeleológico Brasileiro continuaram avançando e, em 2009, tais analistas refinaram e ampliaram a classificação proposta por Auler, Rubbioli e Brandi (2001) caracterizando outras cinco regiões cársticas não carbonáticas (CECAV, 2011).

É importante mencionar que a utilização desta base é aplicável apenas em escalas regionais, devido à necessidade de generalizações durante o mapeamento da geologia elaborada na escala 1:2.500.000 pela Companhia de Pesquisa de Recursos Minerais (2003), base para a construção deste mapa. Para escalas locais é importante realizar a comparação com a geologia local para se obter um melhor 


\section{ORIGINAL ARTICLE}

nível de detalhe. Assim, o atual "Mapa das Regiões Cársticas do Brasil”, elaborado pelo CECAV (2011), apresenta 19 regiões cársticas, a saber: 1) Formação Caatinga (BA), 2) Formação Carajás (PA), 3) Formação Salinas (MG), 4) Formação Vazante (MG), 5) Grupo Açungui (PR e SP), 6) Grupo Apodi (CE e RN), 7) Grupo Araras (MT), 8) Grupo Bambuí (BA, DF, GO, MG e TO), 9) Grupo Brusque (SC), 10) Grupo Corumbá (MS), 11) Grupo Paranoá (DF, GO, MG e TO), 12) Grupo Rio Pardo (BA), 13) Grupo Ubajara (CE), 14) Grupo Una (BA), 15) Grupo Vargem Grande (PI), 16) Grupo Xambioá (PA e TO), 17) Região Cárstica de São João Del Rei (MG), 18) Região Cárstica Quadrilátero Ferrífero (MG) e 19) Supergrupo Canudos (BA e SE),

A região do Grupo Bambuí, conhecida como Província Espeleológica do Bambuí (PEB), ocupa uma área de aproximadamente $150.000 \mathrm{~km}^{2}$ e abrange as porções centro oeste, norte e noroeste de Minas Gerais; leste do Distrito Federal; nordeste de Goiás; sudeste do Tocantins; e oeste da Bahia.

O carste associado à esta Província se desenvolve em duas unidades geológicas: a Formação Sete Lagoas e a Formação Lagoa do Jacaré (ROLDAN; WAHNFRIED; KLEIN, 2004). Na Província Espeleológica do Bambuí encontram-se grandes cavidades como a Toca da Boa Vista (107.000 m) e o Boqueirão (15.170 m) na Bahia; a Lapa de São Mateus III (10.828 m), a Lapa São Vicente I (10.130 m) e o sistema Terra Ronca $(7.500 \mathrm{~m}$ ) em Goiás; assim como a Gruta do Janelão (4.740 m), a Gruta da Morena (4.620 m), a Lapa Nova (4.550 m), o sistema Areias-Chico Bento $(4.610 \mathrm{~m})$, a Gruta do Éden $(2.600 \mathrm{~m})$ e as inúmeras cavernas cadastradas na região de Sete Lagoas e Lagoa Santa em Minas Gerais.

Devido à grande área ocupada pela Província Espeleológica do Bambuí, esta pode ser dividida em distritos. Entretanto, o limite exato destes distritos ainda não foi definido. De acordo com CECAV (2011), atualmente tem-se os distritos de: 1) São Domingos (GO), 2) Formosa, 3) Lagoa Santa (MG), 4) Cordisburgo-Montes Claros (MG), 5) Vazante-Paracatu (MG), 6) Arcos-Pains (MG), 7) Médio São Francisco-São Desidério (BA), 8) Irecê-Campo Formoso (BA) e 9) Alto Paraguaçu (BA). 
Caderno de Geografia (2022) v.32, n.68

ISSN 2318-2962

DOI 10.5752/p.2318-2962.2022v32n.68p.156

\section{ORIGINAL ARTICLE}

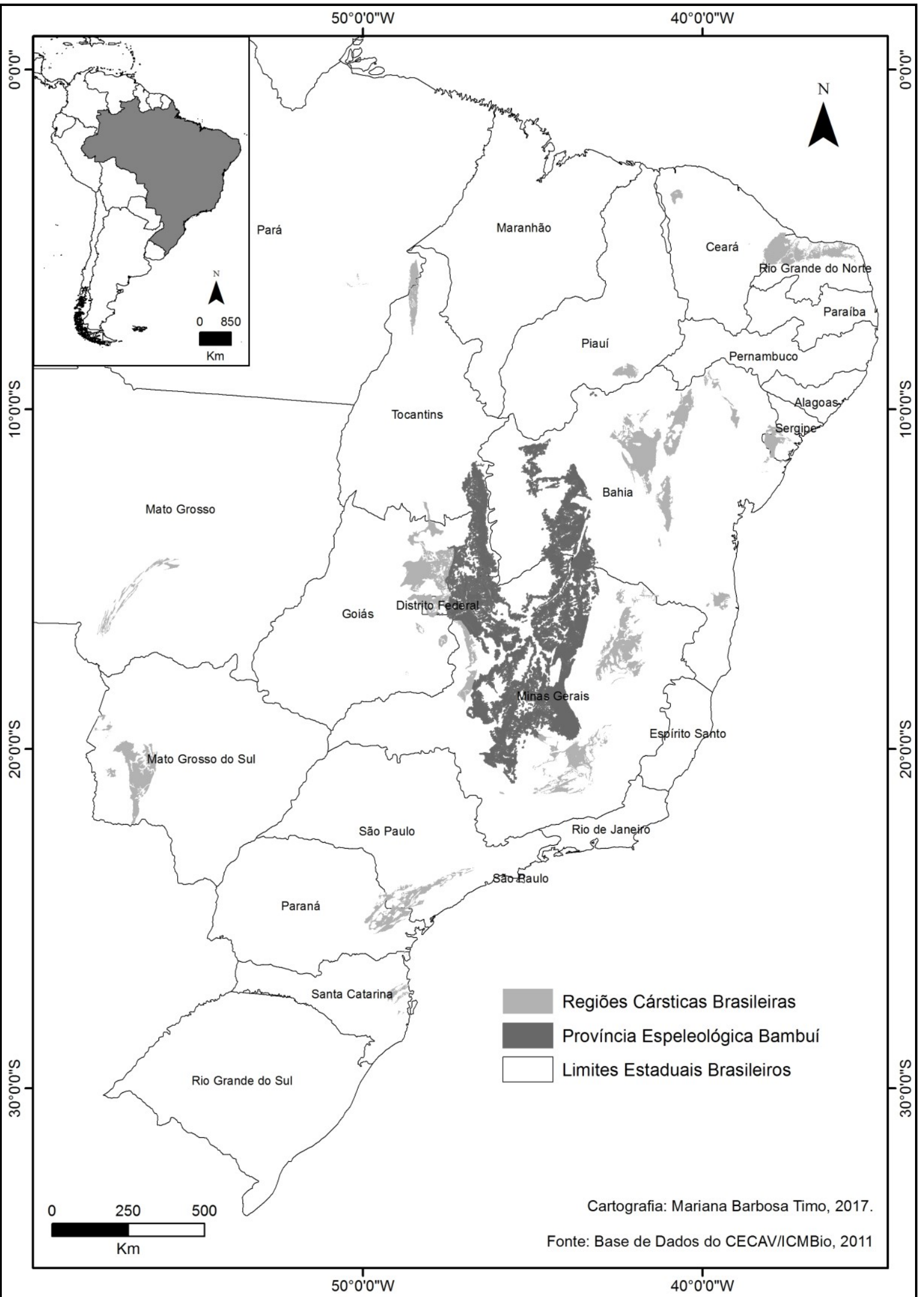

Figura 1 - Províncias Espeleológicas Brasileiras. Dentre as 19 regiões consideradas cársticas pelo CECAV (2011), a região do Grupo Bambuí atualmente se destaca com o maior número de cavidades identificadas. Fonte: Elaborado pela autora a partir da Base de Dados CECAV, 2011. 


\section{ORIGINAL ARTICLE}

O objetivo deste artigo é a caracterização da Região Cárstica de Arcos-Pains, e de seus sistemas cársticos correlatos, a partir da utilização de dados geológicos, geomorfológicos, espeleológicos e hidrográficos. Esta caracterização justifica-se por esta região cárstica abrigar uma das mais importantes reservas minerais de calcário e dolomito do país (PILÓ, 1999). Como consequência, encontram-se instaladas na região diversas empresas de extração destas rochas, além de indústrias cimenteiras e de produção de cal. Tal uso do solo, aliado à precária gestão do Patrimônio Espeleológico, vem ocasionando impactos ambientais significativos no carste regional. Além dos impactos oriundos da mineração, observa-se, ainda, grandes áreas desmatadas para utilização agropastoril e para o extrativismo, além da utilização desordenada do carste para ocupação urbana e fins turísticos.

Apesar do grande Patrimônio Espeleológico existente nesta região cárstica, como as Grutas Brega, Santuário e do Éden (uma das maiores cavernas do estado de Minas Gerais), ainda são escassos os estudos de cunho geomorfológico, principalmente em escala regional, para delinear os aspectos que condicionam a gênese desta paisagem cárstica. São comuns estudos específicos, elaborados no âmbito do licenciamento ambiental, contudo faz-se necessário um estudo sistêmico da Região Cárstica de Arcos-Pains, que favoreça análises mais amplas para orientar a tomada de decisões estratégicas.

\section{CARACTERIZAÇÃO DA ÁREA DE ESTUDO}

A Região Cárstica de Arcos-Pains abrange parcialmente os municípios de Arcos, Córrego Fundo, Doresópolis, Formiga, Iguatama, Pimenta, Piumhi e a totalidade do município de Pains, todos localizados no estado de Minas Gerais, conforme pode ser observado na Figura 2, abaixo. Estes municípios encontram-se na mesorregião denominada Oeste de Minas (IBGE, 2012).

A Região Cárstica de Arcos-Pains é uma faixa de aproximadamente $850 \mathrm{~km}^{2}$, formada por maciços calcários que abrigam centenas de grutas, abrigos e abismos, onde já foram encontrados fósseis, inscrições rupestres, fragmentos e peças cerâmicas, utensílios e ferramentas pré-históricas (PATRIMÔNIO..., 2013, p. 2). O carste regional é bem evoluído, com extensos maciços calcários marcados por diferentes tipos de lapiás (karren). Além disso, apresenta drenagem 


\section{ORIGINAL ARTICLE}

predominantemente subterrânea com a presença de sumidouros, ressurgências, cânions, dolinas e feições residuais, comuns na paisagem cárstica. Estruturas geológicas marcantes, como dobras e falhas, também se fazem presentes.

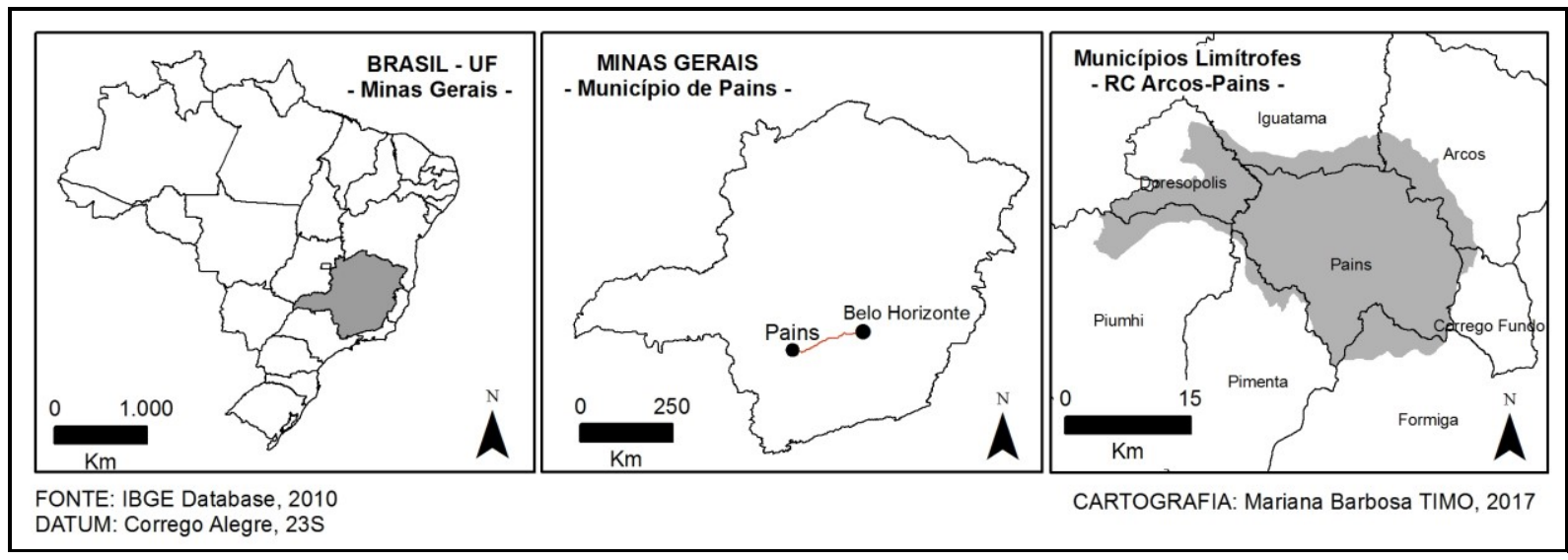

Figura 2 - Mapa de localização da área de estudo.

Fonte: Elaborado pela autora.

A região situa-se no extremo meridional da Bacia Intracratônica do São Francisco, parte sudeste do cráton homônimo (Figura 3), na fronteira com a Faixa de Dobramentos Brasília. A principal unidade litoestratigráfica aflorante é o Supergrupo São Francisco, subordinadamente ocorrem fragmentos da Formação Santo Hilário e da Sequência Serra da Boa Esperança no extremo sul da área, todas de idade neoproterozóica. Além destas unidades, ocorrem coberturas sedimentares, de idade fanerozóica (MARTINS NETO; PINTO, 2001).

As unidades do Supergrupo São Francisco registraram regimes tectônicos muito distintos e conferem à bacia o caráter poli-histórico (DOMINGUEZ, 1993; ALKIMIM; MARTINS NETO, 2001). O modelo geológico evolutivo envolve estágios divergentes, bacias tipo rifte-margem passiva e estágio convergente relacionado à colagem do Gondwana, seguido do desenvolvimento de bacias de retro-arco (backarc) e de ante-país (foreland).

A Bacia do São Francisco constitui importante fonte de exploração calcária e de ardósias (DARDENE, 1978; (DARDENE; SCHOBBENHAUS, 2000; DOMINGUEZ, 1993). A unidade de maior expressão areal da bacia é o Supergrupo São Francisco, composto pelos Grupos Macaúbas e Bambuí. A área de estudo está inserida na Província Espeleológica do Grupo Bambuí, composta por uma sucessão de rochas marinhas carbonáticas e pelíticas que, por vezes, passa a conglomerados 


\section{ORIGINAL ARTICLE}

e arenitos registrando uma generalizada transgressão marinha. Para esse setor sudoeste da bacia recomenda-se a utilização do conceito Subgrupo Paraopeba (DARDENE; SCHOBBENHAUS, 2000), considerado indiviso (CPRM, 2007). Para Muzzi Magalhães et al. (1989), é representado pelas Formações Carrancas, Samburá, Sete Lagoas, Serra de Santa Helena, Lagoa do Jacaré e Serra da Saudade, que constituem da base para o topo, respectivamente, as seguintes litofácies: conglomerática; pelítica (argilitos com estratificação plano-paralela); carbonática (calcilutitos, margas e calcarenitos com laminações paralelas e cruzadas, calcarenitos dolomíticos pretos, dolarenitos calcíticos e calcarenitos estromatolíticos), e psamo-pelítica (argilitos e siltitos), Figura 4.

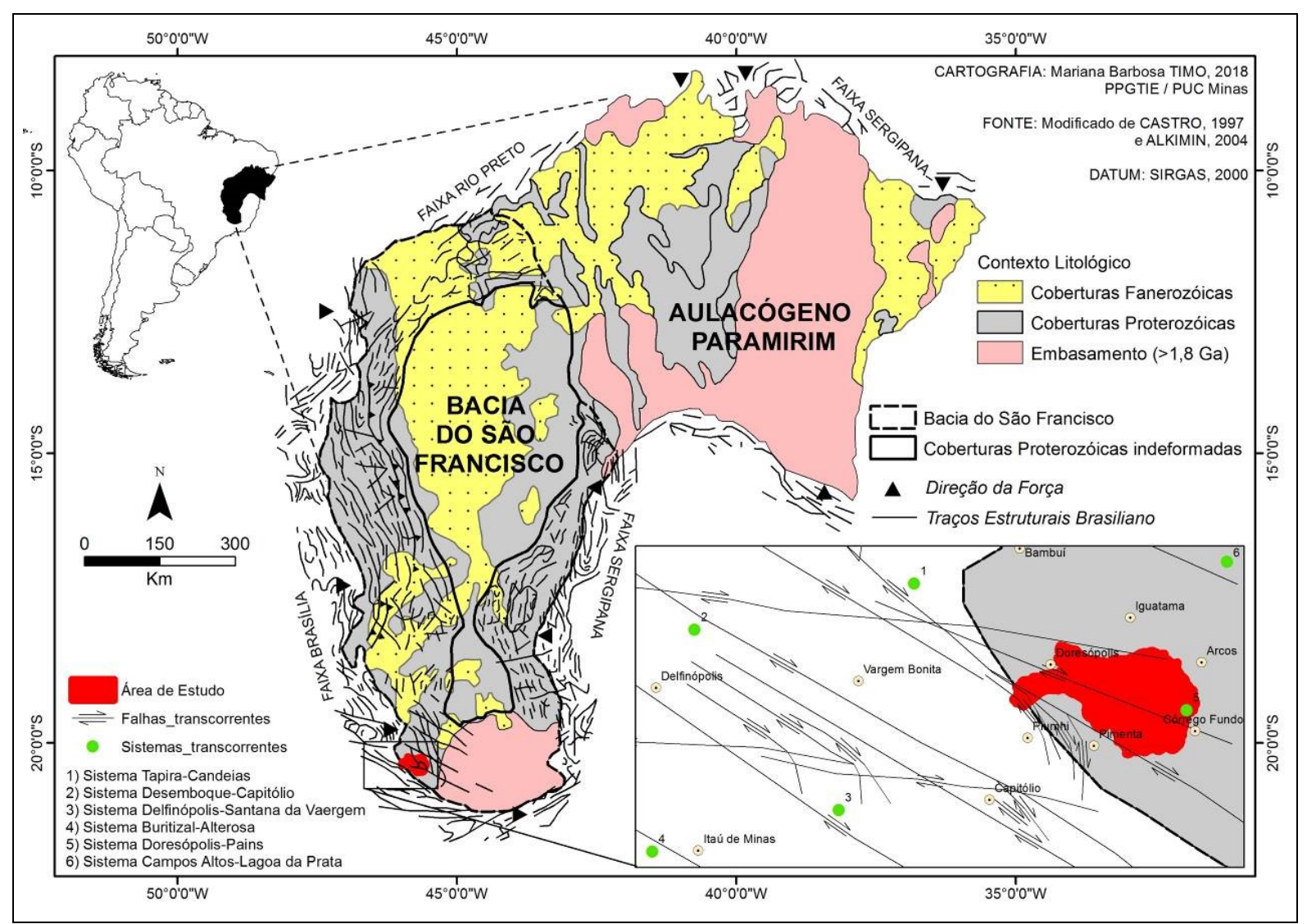

Figura 3 - Localização do Cráton São Francisco e suas faixas no contexto geotectônico regional, bem como posicionamento da região estudada, sudeste da região, indicada na cor vermelha.

Fonte: Modificado de Martins Neto e Pinto, 2001.

O arcabouço geológico-estrutural da parte sul da Bacia SanFranciscana foi descrito por Alkmim e Martins Neto (2001). De acordo com os autores supracitados, essa bacia apresenta três compartimentos estruturais, sendo os mesmos assim 


\section{ORIGINAL ARTICLE}

definidos: 1) A oeste (W), representando a zona externa das faixas Brasília e Rio Preto; 2) A leste (E), englobando as extremidades da Faixa Araçuaí; e 3) Porção central (C), representado pelo Alto de Sete Lagoas, onde as unidades précambrianas praticamente não foram afetadas. A área estudada encontra-se no Compartimento Oeste (W), na porção mais a sul. Esta região sofre importante influência das faixas Brasília e Rio Preto, cuja porção externa está representada por um cinturão de dobramentos e cavalgamentos de ante-país. As unidades envolvidas constituem rochas do Grupo Bambuí, ora denominado Subgrupo Paraopeba, indiviso.

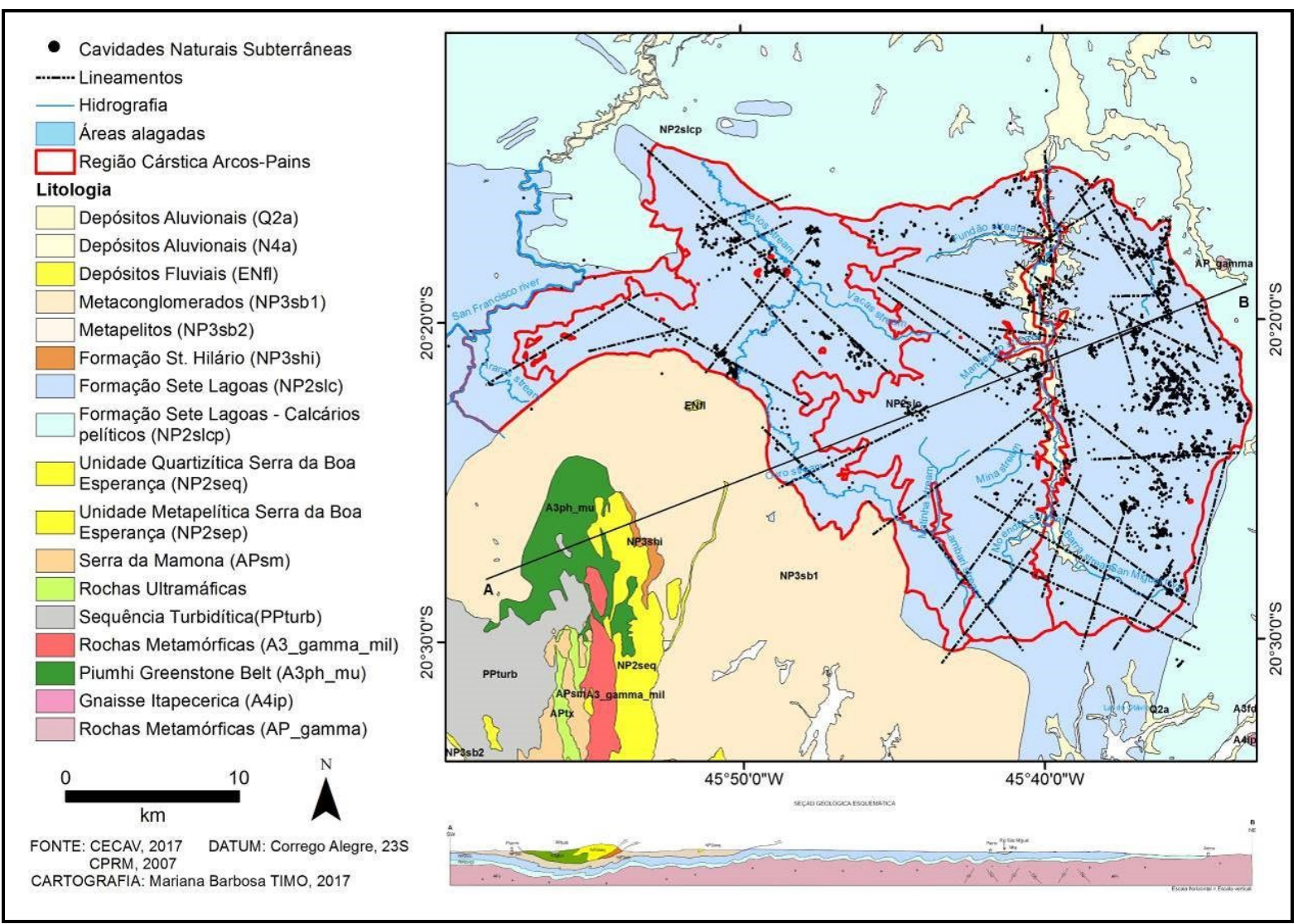

Figura 4 - Mapa geológico da Região Cárstica Arcos-Pains.

Fonte: Modificado de CPRM, 2007.

Segundo Martins (2013), o relevo da região onde se localiza a Região Cárstica Arcos-Pains pode ser dividido em dois grandes domínios morfoestruturais: o Cráton São Francisco e a Faixa de Dobramentos Brasília. Ainda considerando o trabalho da autora, o complexo morfoestrutural do Cráton São Francisco pode ser divido em três unidades morfoestruturais distintas. Estas são classificadas em Depósitos 


\section{ORIGINAL ARTICLE}

Aluvionares Cenozóicos, Bacia Sedimentar do São Francisco e Embasamento. Tal classificação considera a gênese, idade e tipos litológicos das unidades. A autora sugere, ainda, que a Faixa de Dobramentos Brasília pode ser denominada Sistema de Empurrões de Piumhi (Piumhi Greenstone Belt).

Assim, considerando a classificação elaborada por Martins (2013), a área desta pesquisa se localiza na unidade morfoestrutural classificada como a Bacia Sedimentar do São Francisco. Tal unidade morfoestrutural desenvolveu-se ao longo da drenagem do rio São Francisco, inicialmente nos vales dos grandes rios orientados por fraturas, alargando-se posteriormente por processos de aplainamento, predominando, portanto, formas aplainadas, superfícies onduladas e pedimentos ravinados, exceto nas áreas cársticas que apresentam morfologia peculiar (SUPRAM, 2013).

De acordo com o CETEC (1983), o arranjo espacial das formas de relevo da Depressão do Alto São Francisco resulta da conjugação de fatores litológicos e estruturais associados a eventos de dissecação, aplainamento, acumulação fluvial e dissolução das rochas. A Faixa de Dobramentos Brasília relaciona-se com as rochas do Grupo Canastra que são constituídas por quartzitos e filitos, possivelmente provenientes do Cráton São Francisco, e afloram a oeste de Minas Gerais (BAPTISTA et al. 2010). A dissecação do relevo é mais marcante a sudoeste da unidade, onde os litotipos do Grupo Bambuí são interceptados pela cadeia dobrada da Serra da Canastra.

A região encontra-se dentro dos limites do Bioma Cerrado (IBGE, 2004). Porém, devido às suas características edáficas e climáticas, estão presentes variações do Bioma Mata Atlântica, ou seja, a área encontra-se em um ambiente de transição entre os biomas da Mata Atlântica e do Cerrado. No Brasil, nas áreas de cerrado ocorre largamente a fitofisionomia classificada como Mata Seca (Floresta Tropical Seca) associada às rochas carbonáticas (RODRIGUES, 2011). De acordo com o autor, em Minas Gerais, as Matas Secas estão associadas, em grande parte, à Província Espeleológica do Grupo Bambuí (Grupos Bambuí e Formação Vazante) e à Formação Salinas no Vale do Jequitinhonha, com ocorrências nos municípios de Arcos, Bambuí, Cordisburgo, Itacarambi, Januária, Lagoa Santa, Monjolos, Montes Claros, Pains, Salinas, Santo Hipólito, Unaí e Vazante. 


\section{ORIGINAL ARTICLE}

Em toda a Unidade Espeleológica Arcos-Pains a vegetação já foi modificada, contudo ainda restam algumas regiões remanescentes aparentemente intactas. $\mathrm{Na}$ maior parte da região observa-se que as Matas Secas ocorrem apenas sobre as feições residuais (Figura 5). No restante da área a pressão antrópica se faz presente por meio de atividades tradicionais como a pecuária extensiva e cultivos para o abastecimento regional (e.g.: feijão e milho).

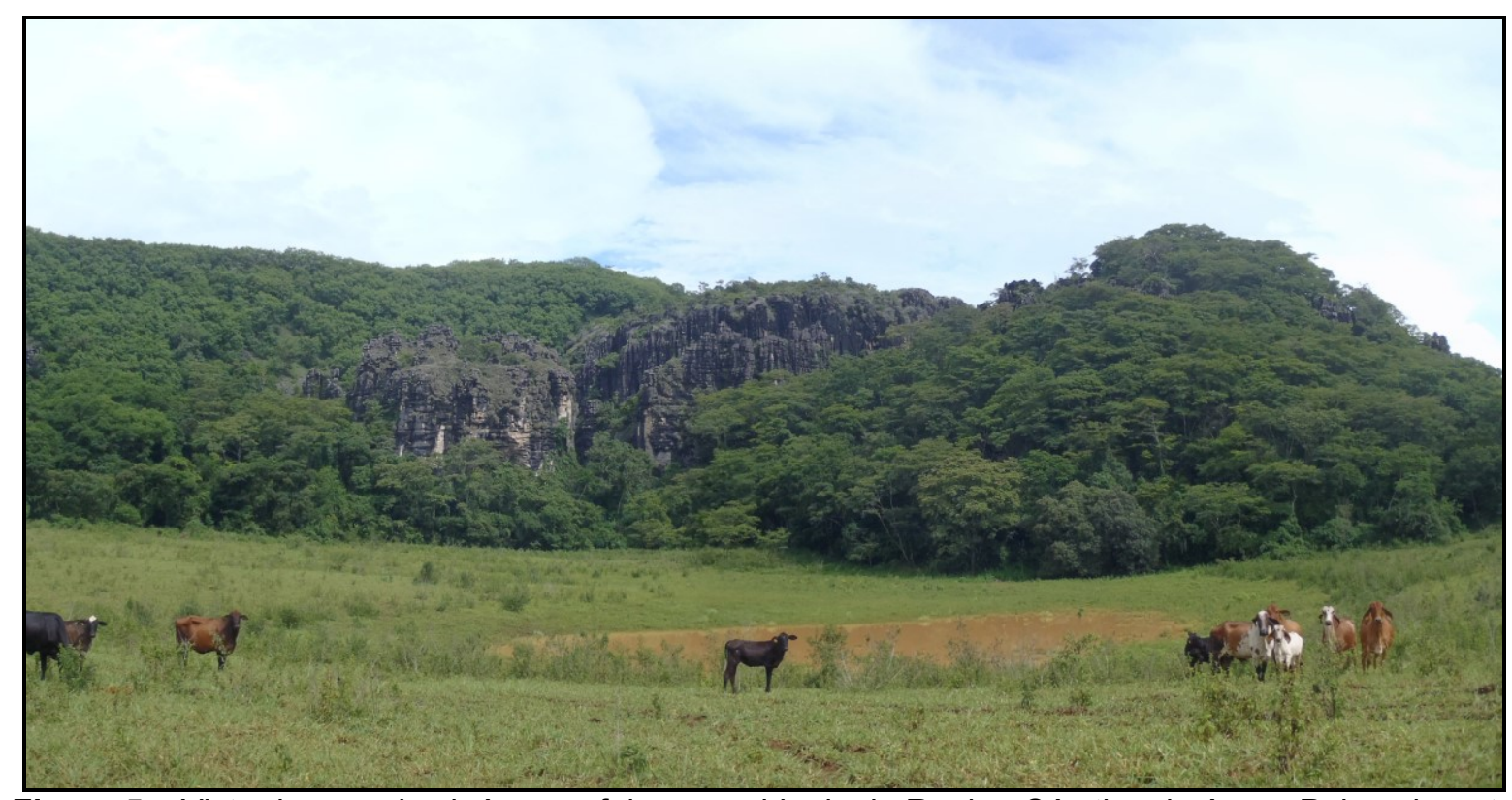

Figura 5 - Vista de uma das inúmeras feições residuais da Região Cárstica de Arcos-Pains, durante o período chuvoso. Notar a ocorrência da Mata Seca apenas sobre as feições residuais.

Fonte: Mariana Barbosa Timo, 2013.

Segundo a classificação de Köppen-Geiger, o clima da Região Cárstica de Arcos-Pains é do tipo Aw, tropical úmido de inverno seco e verão chuvoso, a temperatura média no mês mais frio é superior a $18^{\circ} \mathrm{C}$ e os totais pluviométricos variam entre 1.000 e $1.500 \mathrm{~mm}$. A umidade média anual é de $67,8 \%$ e os meses mais úmidos são dezembro e janeiro, cuja média mensal atinge a 74,8\% (MAPEAR, 2003). Normalmente a atmosfera é calma, entretanto, em agosto ocorrem ventanias que levantam poeira e cinzas de queimadas a grandes altitudes, através de redemoinhos. A temperatura média compensada anual da região foi de $20,7^{\circ} \mathrm{C}$, com máximas de $28,5^{\circ} \mathrm{C}$ e mínimas de $14,6^{\circ} \mathrm{C}$, e umidade relativa em torno de $80 \%$ (INMET, 2013). 


\section{ORIGINAL ARTICLE}

A área em estudo está localizada na porção do Alto São Francisco e as principais drenagens da região correspondem ao rio São Miguel e ao ribeirão dos Patos, ambos situados na margem direita do rio São Francisco, no centro-oeste do estado de Minas Gerais. Apesar de situados em área cárstica, o curso principal destas drenagens é perene e superficial na sua maior parte, onde os usos do solo abrangem campos de pastagens para pecuária, agricultura, ocupação urbana, mineração e beneficiamento de rochas carbonáticas (HADDAD, 2007).

O balanço hídrico de Thornthwaite-Mather para a área total das duas bacias hidrográficas demonstra a existência de dois períodos distintos, um com excedente de água, de novembro a abril (período chuvoso), e outro com déficit de água, de maio a setembro (período seco), com reposição em outubro (MENEGASSE et al., 2002).

Os sistemas aquíferos da bacia do São Francisco foram individualizados por Mourão et al. (2001), com base nos aspectos litoestratigráficos e na natureza da permeabilidade das rochas. $\mathrm{Na}$ Região Cárstica Arcos-Pains ocorrem, principalmente, dois sistemas aquíferos representados por rochas carbonáticas précambrianas pertencentes ao Supergrupo Paraopeba, Grupo Bambuí (Formações Lagoa do Jacaré, Serra de Santa Helena e Sete Lagoas) e aos Grupos Vazante e Paranoá: o Aquífero Cárstico e o Aquífero Cárstico-Fissurado.

A bacia hidrográfica do ribeirão dos Patos cobre parte dos municípios de Pains, Pimenta, Doresópolis e Iguatama. O rio possui direção geral de fluxo de sul para norte, com cerca de $50 \mathrm{~km}$ de extensão. O seu padrão morfológico é meandrante até sua confluência com o rio São Francisco. O rio São Miguel possui direção geral S/N, cerca de $40 \mathrm{~km}$ de extensão e uma área de drenagem de aproximadamente 525 $\mathrm{km}^{2}$. Ela abrange parte dos municípios de Pains, Arcos, em sua maior parte, seguida por áreas dos municípios de Iguatama, Formiga e Córrego Fundo. O seu padrão morfológico é meandrante até sua confluência com o rio São Francisco, a $630 \mathrm{~m}$ de altitude. 


\section{COMPARTIMENTAÇÃO GEOMORFOLÓGICA}

A evolução da paisagem é controlada por diferentes forças. Estas forças são provenientes tanto dos movimentos tectônicos verticais, resultantes da interação entre placas tectônicas (processos endógenos), quanto da erosão e deposição (processos exógenos), que são controlados por uma gama de processos cuja importância relativa depende das condições climáticas locais, vegetação e tipo de rocha (KAUFMANN, 2003).

Os relevos desenvolvidos sobre rochas solúveis (calcários, gesso, sal, evaporitos) além de terem seus modelados esculpidos e estruturados pelos processos endógenos e exógenos, são ainda corroídos pelos processos químicos de dissolução e erosão do calcário pelas águas meteóricas (superficiais), vadosas e freáticas (subterrâneas). O enriquecimento do escoamento superficial com dióxido de carbono torna a água pouco agressiva. Contudo capaz de remover calcita por dissolução química. A potencialidade da água em reter o $\mathrm{CO} 2$ varia em função da pressão parcial do gás carbônico no ar e da temperatura da água. Águas de temperaturas mais baixas tem uma potencialidade maior de reter gás carbônico. Por outro lado, temperaturas mais altas aceleram a dissolução, porem diminuem o $\mathrm{CO} 2$ dissolvido em função da baixa potencialidade da água em reter o $\mathrm{CO} 2$. Isto explica a ocorrência de diferentes formas cársticas nas diferentes zonas climáticas do globo (KOHELER, 1989). KAUFMANN, 2003 KOHELER, 1989

A Província Cárstica Arcos-Pains-Doresópolis situa-se no alto Rio São Francisco. É constituída por carste ruiniforme erodido, cavernas e escarpas em corpos contínuos ou isolados de calcários. Estes corpos são cortados por diáclases e abismos e separados por relevo aplainado com dolinas, uvalas, sumidouros, surgências e vales cegos. Segundo Barbosa (1961) a evolução da morfologia cárstica reflete variações pluviométricas e paleoclimáticas. Rolff (1953) sugeriu que falhas e fraturas exerceriam um controle sobre os fluxos d'água. $\mathrm{O}$ relevo cárstico na região tem sido alvo de estudo desde a década de 50, destacando-se os trabalhos pioneiros de Rolff (1953), Tricart (1956) e Barbosa (1961). Trata-se de uma região bastante arrasada, onde as rochas carbonatadas, mais resistentes a erosão, formam escarpas abruptas e feições cársticas características (MADALOSSO; VERONESE, 1978). 


\section{ORIGINAL ARTICLE}

Santos (2002) atribui a morfogênese cárstica regional à neotectônica e sua associação entre soerguimento e cisalhamento transcorrente N50W. Considerando o autor, a evolução cronológica desta região cárstica se deu nas seguintes etapas (Figura 6): 1) Durante o Eoceno a região estava aplainada. O princípio do processo de carstificação gerou dolinas possivelmente controladas por falhas passivas N50W a N70W. Com o soerguimento do Alto Estrutural de Bom Despacho, fraturas N-S foram abertas e aproveitadas para a formação da primeira geração de cavernas da província. 2) Em consequência da ativação do carste, formam-se os grabens de Arcos (N30W) e Doresópolis (N40W). Com isto, o nível de base local é rebaixado, favorecendo a gênese do cânion do rio São Francisco. Outra consequência deste processo é a erosão da cobertura pelítica na porção sul da província. As cavernas da $1^{a}$ geração são então esvaziadas e os topos dos maciços calcários começam a ser expostos e lapiezados. 3) Uma segunda geração de cavernas começa a se formar a partir do novo nível de base estabelecido, provavelmente no Pleistoceno Inferior. A formação de dolinas passa então a ser controlada por falhas de distensão ativas nas direções N30W e N40W. Com a parte sul mais soerguida (embasamento) o processo de dissecação atinge os gnaisses do embasamento, alimentando os terraços com quartzo. 4) O soerguimento continua mais intenso a sul, mantendo o arqueamento na direção N-S. Este processo favorece a incisão dos principais cursos d'água da província, o ribeirão dos Patos e o rio São Miguel. Durante a incisão, o nível de base é mais uma vez rebaixado, possibilitando que dolinas e uvalas funcionem como sumidouros na porção sul. 5) Fase atual de carstificação. As cavernas encontram-se secas em sua maioria. 
Caderno de Geografia (2022) v.32, n.68

ISSN 2318-2962

DOI 10.5752/p.2318-2962.2022v32n.68p.156

\section{ORIGINAL ARTICLE}

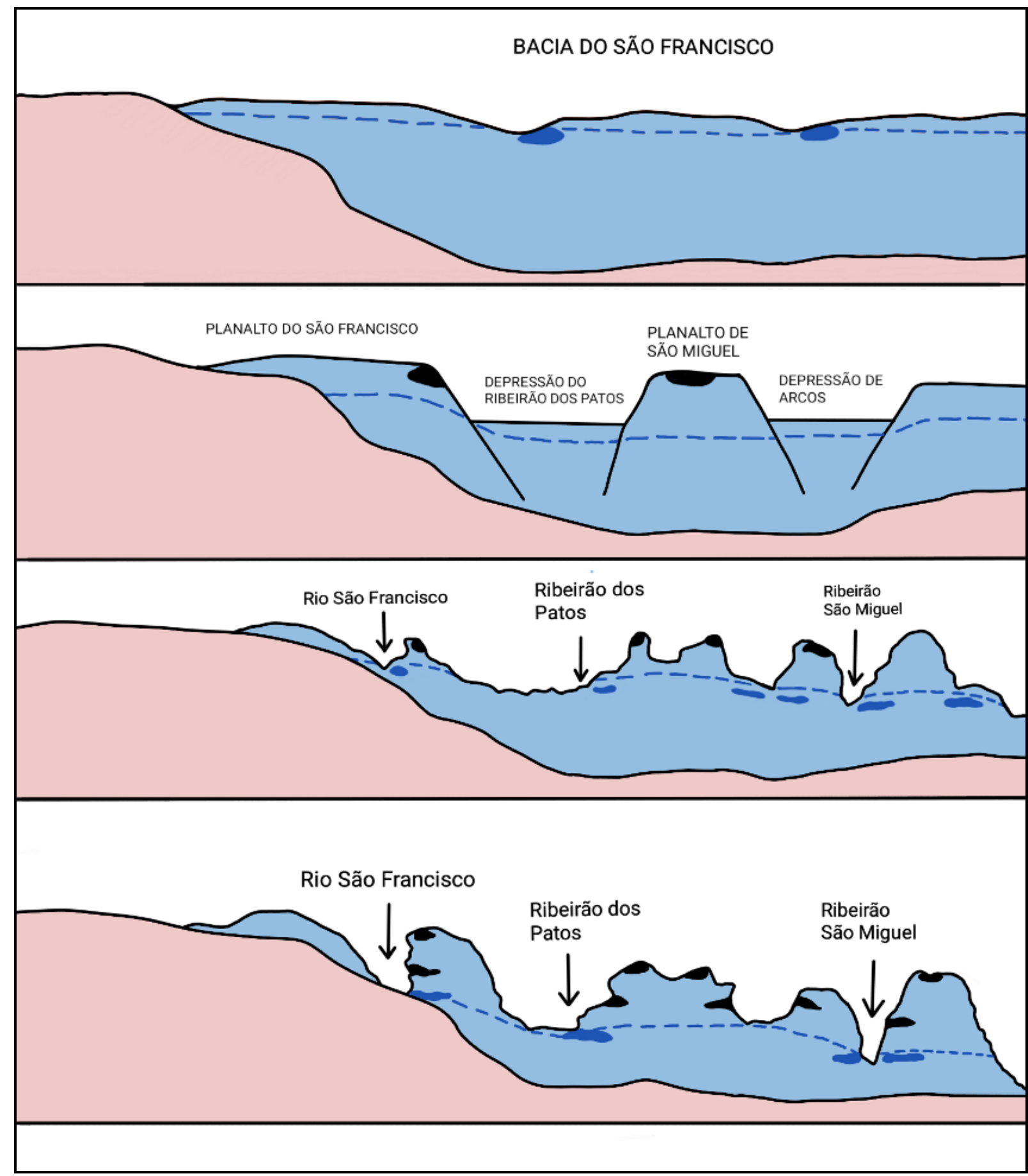

Figura 6 - Esquema simplificado (sem escala) da evolução cronológica da Região Cárstica ArcosPains. A cor magenta representa o Embasamento $(>1,8 \mathrm{Ga})$, a cor azul representa as rochas carbonáticas, a linha trazejada em azul escuro representa o nível da água e as áreas pretas representam os cavernamentos. Fonte: Desenhado por Juliana Barbosa Timo, a partir de Santos (2002). 


\section{ORIGINAL ARTICLE}

Quanto à sua compartimentação geomorfológica, Pizarro (1998) divide a Região Cárstica Arcos-Pains (no sentido E-W) em quatro blocos identificados pelos principais cursos d'água que os cortam e suas peculiaridades geológicas e geomorfológicas. Apesar de não apresentar a delimitação, o autor dividiu os blocos em: 1) Bloco São Miguel, 2) Bloco Intermediário, 3) Bloco Ribeirão dos Patos e 4) Bloco São Francisco.

O Projeto Arcos Pains Espeleologia (PROAPE), executado pela Sociedade Excursionista Espeleológica (SEE) no período de 2010 a 2012, diferenciou a região em três domínios espeleogenéticos, como resultado da integração dos conhecimentos da geologia local com os do levantamento espeleológico efetuado (SEE, 2012; TEIXEIRA-SILVA et al., 2013). Para os autores, o Domínio Espeleogenético I, caracteriza-se pela ocorrência predominante de rochas indeformadas e situando-se a leste do rio São Miguel. O Domínio Espeleogenético II, caracteriza-se pela ocorrência predominante de rochas medianamente deformadas e situa-se entre o rio São Miguel e o ribeirão dos Patos. O Domínio Espeleogenético III caracteriza-se pela ocorrência de rochas mais deformadas e localiza-se a oeste do ribeirão dos Pato. O cânion do rio São Francisco foi considerado neste domínio.

Em 2013, Martins propôs a compartimentação topográfica da Folha Piumhi, e Timo (2014) apresentou a delimitação da Região Cárstica Arcos-Pains, incluindo uma atualização da nomenclatura dos domínios espeleológicos, baseada nas definições estabelecidas por Martins (2013). Neste trabalho utilizaremos a nomenclatura proposta por Martins (2013), por ser a mais atualizada, contudo realizaremos atualizações nos limites apresentados por Timo (2014), devido ao grau de aprofundamento nas pesquisas deste carste alcançado com esta tese (Erro! Fonte de referência não encontrada.). 


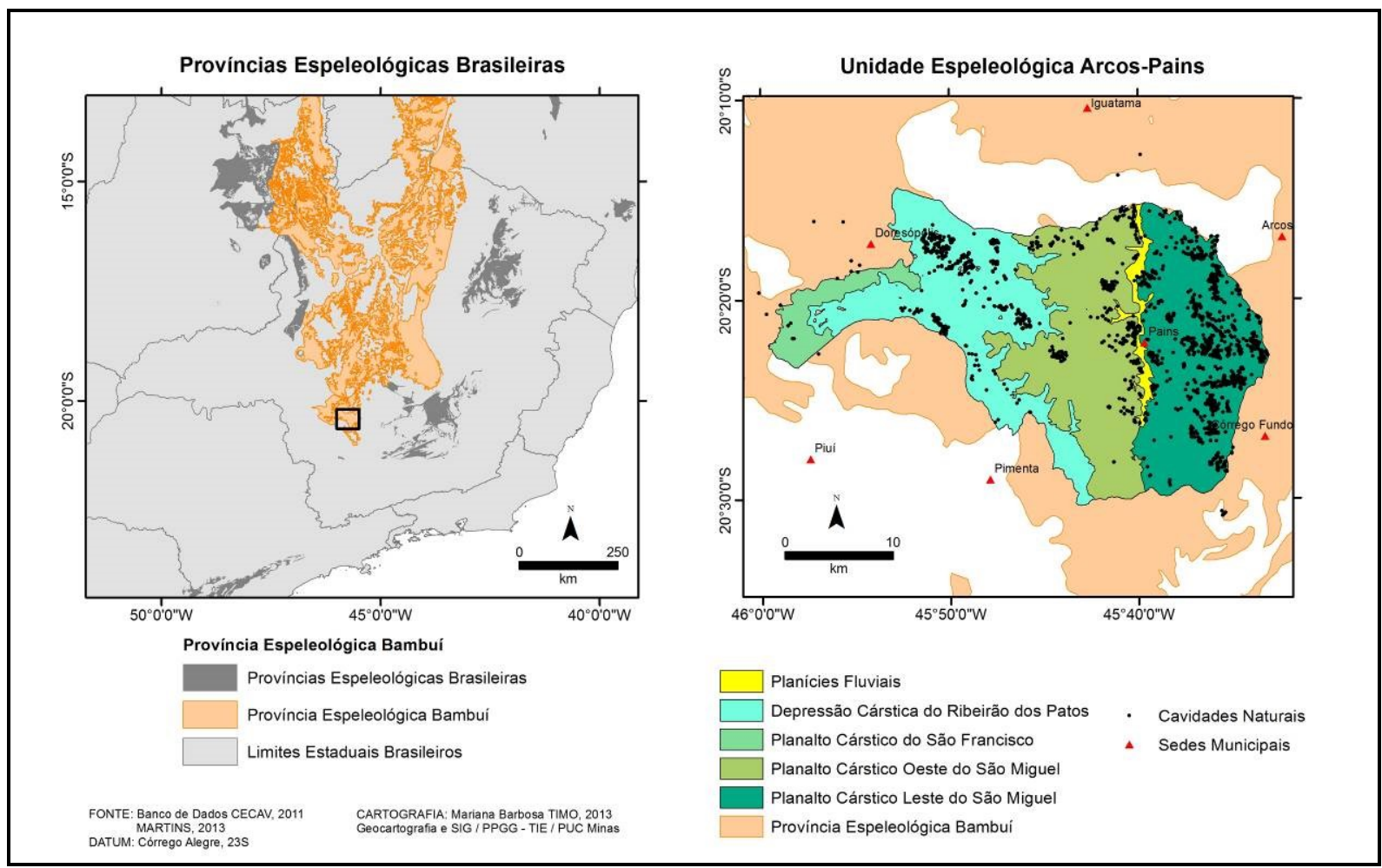

Figura 7 - Compartimentação Geomorfológica da Região Cárstica Arcos-Pains.

Fonte: Elaborado pela autora.

Muitos fatores geológicos e hidrológicos influenciam o desenvolvimento do carste e nem todas as feições cársticas estão presentes ou bem desenvolvidas em qualquer área cárstica. Cvijić (1895/2017) classificou os tipos de carste usando como base as características das feições geomorfológicas em holocarste e merocarste, mas esta classificação não é muito comum nos dias atuais. Ford, Palmer e White (1988) propuseram uma nova classificação, que será utilizada neste trabalho. De acordo com os autores o carste da região de Arcos-Pains pode ser classificado em duas categorias: 1) fluviocarste, onde as feições geomorfológicas dominantes são vales que tiveram sua gênese condicionada por rios superficiais que foram parcialmente ou completamente capturados pelos condutos subterrâneos das cavidades. Neste tipo de carste os principais rios permanecem na superfície porque o seu fluxo é muito grande para ser absorvido pelo aquífero ou porque a rede de canais subterrâneos ainda não se estendeu para interceptar as nascentes. $\mathrm{Na}$ maioria das vezes este carste se desenvolve em rochas carbonáticas que têm baixa permeabilidade intrínseca; e 2) carste de dolinas, onde praticamente não existem cursos d'água em superfície e quase toda a drenagem foi capturada e circula 
Caderno de Geografia (2022) v.32, n.68

ISSN 2318-2962

DOI 10.5752/p.2318-2962.2022v32n.68p.156

\section{ORIGINAL ARTICLE}

internamente nas dolinas. Este tipo de carste é típico de rochas carbonáticas que possuem alta permeabilidade intrínseca.

A seguir serão descritas as Compartimentações Geomorfológicas propostas para a Região Cárstica Arcos-Pains.

\section{Planalto Cárstico do Leste São Miguel (Bloco São Miguel)}

Corresponde à porção da província onde é possível a visualização de toda a sequência estratigráfica das Fácies Carbonáticas de Muzzi Magalhães et al. (1989). Apesar das ocorrências de calcário mais contínuas serem predominantes, há porções onde as intercalações de rochas pelíticas estão presentes e feições residuais como torres, verrugas e banquetas são recorrentes (PIZARRO, 1998).

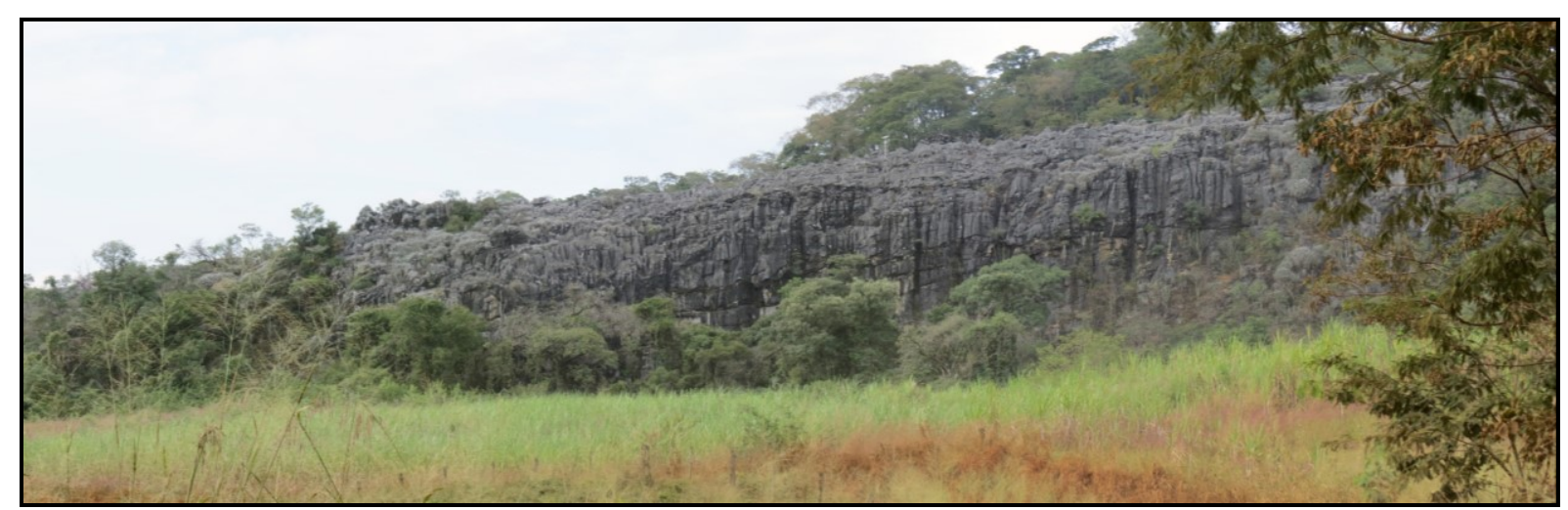

Figura 8 - Maciços altos e contínuos observados na região de Corumbá, Pains (MG).

Fonte: Bruno Durão Rodrigues, 2013.

Este bloco apresenta os maiores e mais contínuos maciços (Figura 8), marcados por lapiás (karren), atingindo alguns quilômetros de extensão e alturas de até $50 \mathrm{~m}$ (PIZARRO, 1998). No entorno dos maciços, a superfície apresenta declividade moderada representando amplas colinas (MARTINS, 2013). São frequentes as feições exocársticas, os sistemas de sumidouros-ressurgências, vales cegos, dolinas e uvalas. Além disso, localiza-se nesta Unidade Geomorfológica algumas feições representativas do relevo cárstico como a Lagoa do Retiro e a Uvala de Corumbá (Figura 9), além do Distrito de Corumbá. 


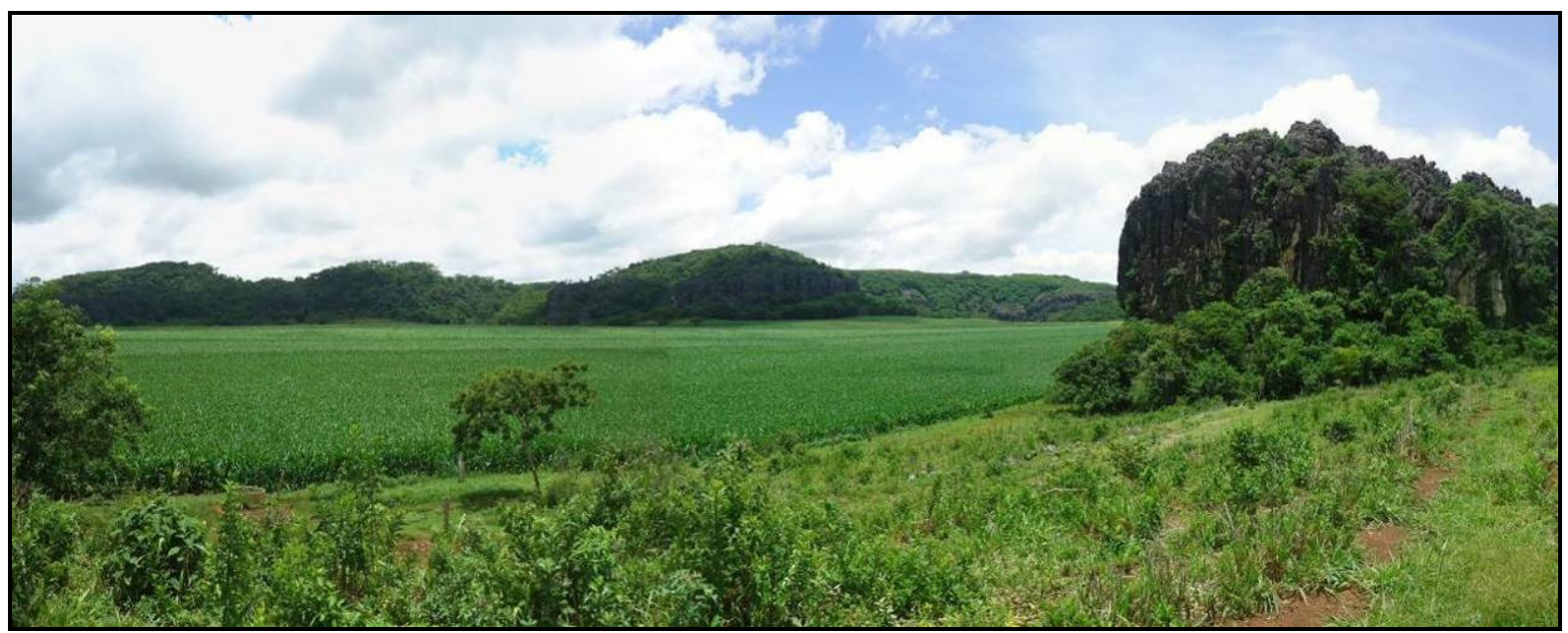

Figura 9 - Vista geral da Uvala de Corumbá no período chuvoso com detalhe para os afloramentos ao fundo, $\operatorname{Arcos}(M G)$.

Fonte: Mariana Barbosa Timo, 2013.

As principais estruturas que controlam o endocarste na região são as fraturas subverticais e os planos de acamamento horizontais. Este Bloco engloba o maior número de cavidades registradas até o momento nesta Unidade Espeleológica. Destacam-se as grutas do Éden, Coqueiro I, II e III, Isaías e Paraíso. Vale destacar que nesta Unidade Geomorfológica também foram registradas as pinturas rupestres (Figura 10) mais relevantes, até o momento, em toda a Unidade Espeleológica Arcos-Pains.

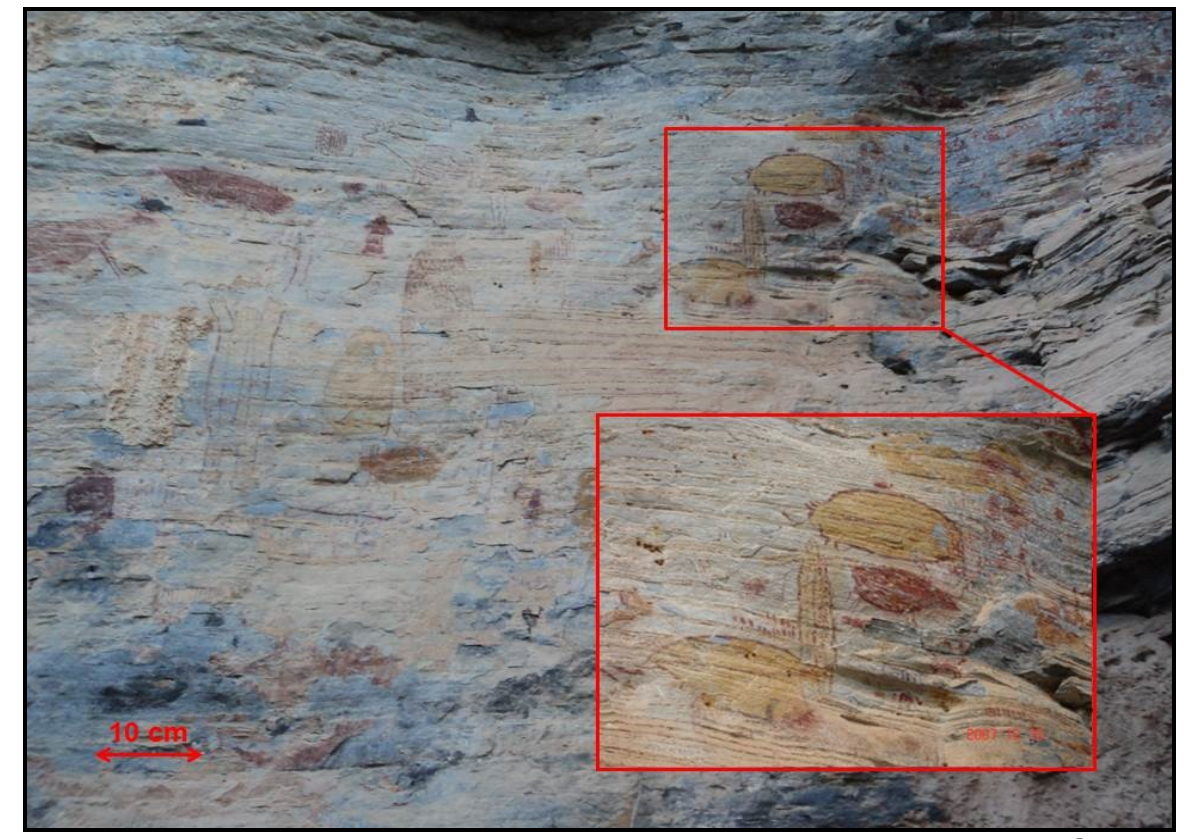

Figura 10 - Pinturas rupestes loalizadas na região da Posse Grande, Arcos (MG). Fonte: Mariana Barbosa Timo, 2013. 


\section{ORIGINAL ARTICLE}

\section{Planalto Cárstico do Oeste São Miguel (Bloco Intermediário)}

Compreende uma faixa norte-sul, a oeste do Planalto Cárstico do Leste São Miguel, limitado a leste pela localidade da Mina, a sudoeste pela Vila Costina, a oeste pela Vila Capoeirão e a localidade dos Cunhas (PIZARRO, 1998). Geomorfologicamente hospeda colinas e cristas suaves, típicas de rochas pelíticas, com afloramentos calcários esparsos e/ou maciços. O padrão das drenagens é geralmente dendrítico à subparalelo, orientado principalmente segundo direções EW e NE-SW, apresentando sistemas de sumidouros-ressurgências com dolinas alagadas.

A porção centro-sul desta Unidade Geomorfológica é caracterizada por lentes de calcários esparsas, afloramentos métricos e maciços isolados devido à interferência das rochas pelíticas (Figura 11). A porção norte é constituída por um conjunto de maciços contínuos bastante deformados por processos tectônicos.

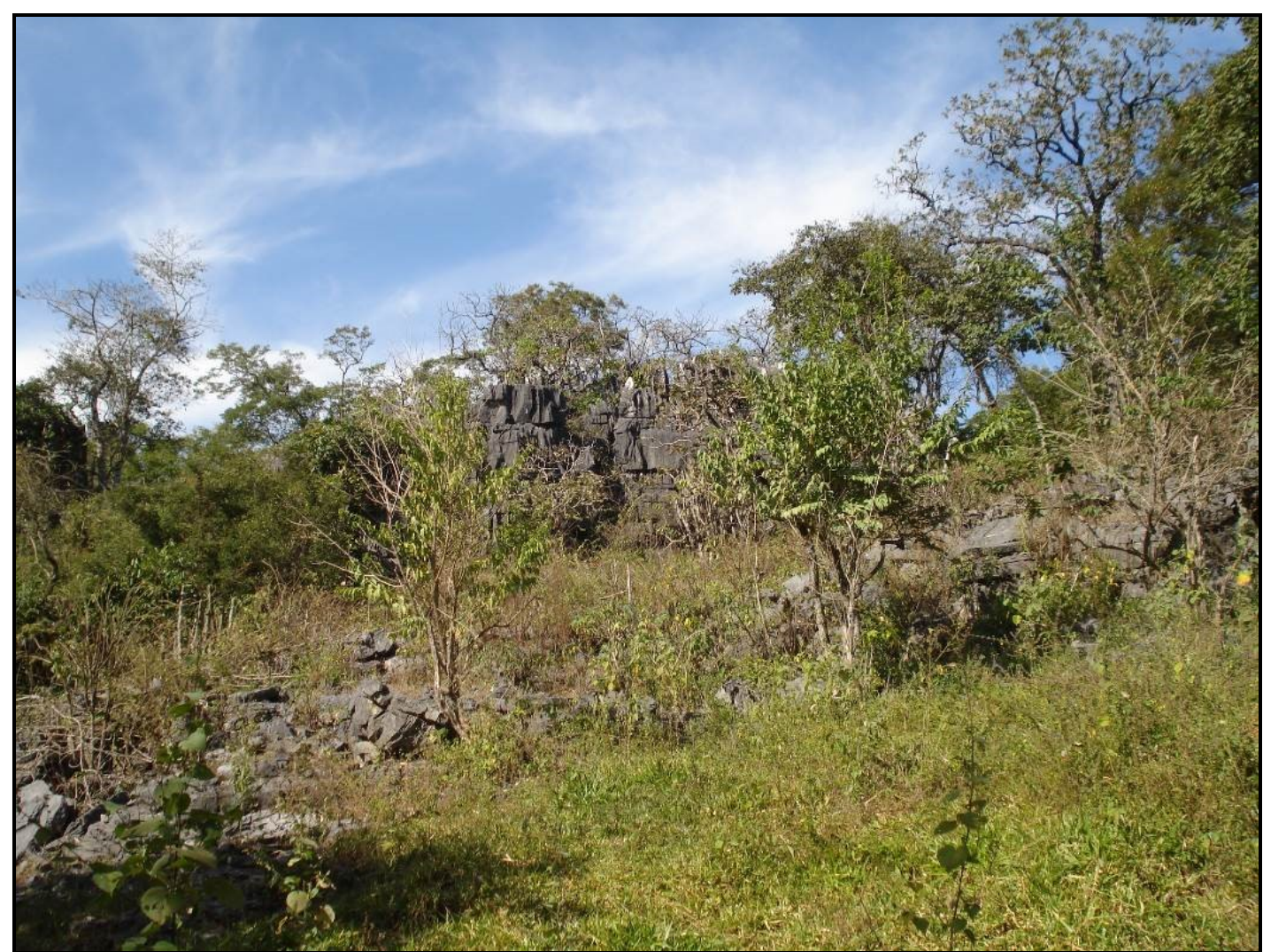

Figura 11 - Maciços isolados de dimensões métricas com influência de rochas pelíticas, Distrito da Mina, Pains (MG). Fonte: Mariana Barbosa Timo, 2009. 


\section{ORIGINAL ARTICLE}

As cavernas são controladas, principalmente, por estruturas como os planos axiais de dobras, clivagens de fraturas e planos de falhas. Na porção leste as principais cavernas são a gruta da Ressurgência e sumidouro da Loca D’Água. A oeste destacam-se a gruta do Davi e a Toca do Capoeirão. A sul destaca-se a gruta do Recanto e a Loca do Teto Alto, próximo ao Distrito da Mina.

\section{Depressão Cárstica do Ribeirão dos Patos (Bloco Ribeirão dos Patos)}

Esta Unidade Geomorfológica é caracterizada por apresentar afloramentos calcários em praticamente toda a sua extensão (MARTINS, 2013). Segundo a autora, esta área é bastante plana e está alagada em alguns pontos e em outros está suscetível à inundação.

Estruturalmente apresenta maciços calcários contínuos, orientados segundo direções NW-SE, decorrentes de sistemas de falhamentos transcorrentes relacionados ao lineamento Doresópolis-Pains. A geomorfologia é caracterizada pelos extensos maciços calcários, dolinas, uvalas, sumidouros, surgências e campos de lapiás com grande beleza cênica. Destaque para a Lagoa dos Martins (Figura 14) que, segundo Martins (2013), é um exemplo representativo de uma das feições mais características desta Unidade Geomorfológica.

As cavernas mais representativas são as grutas do Brega (Figura 12 e Figura 13), Santuário e Zezinho Beraldo.

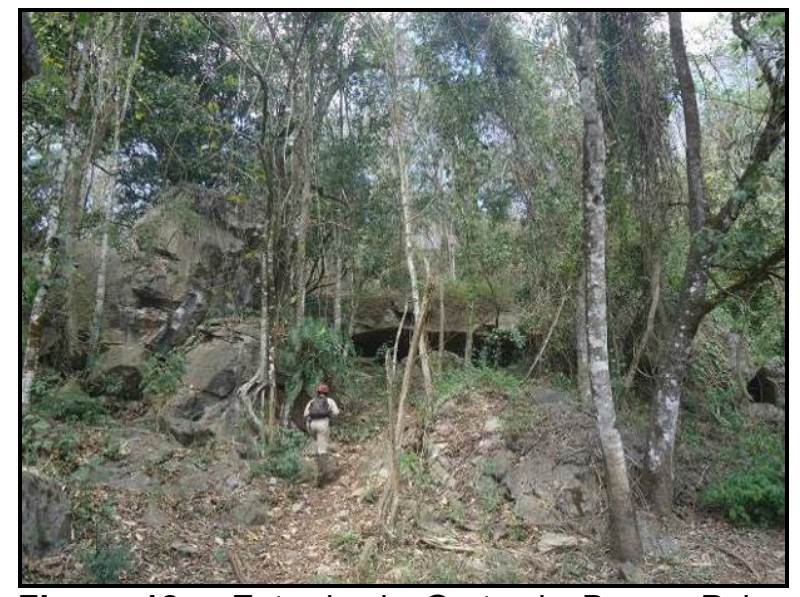

Figura 12 - Entrada da Gruta do Brega, Pains (MG). Fonte: Mariana Barbosa Timo, 2013

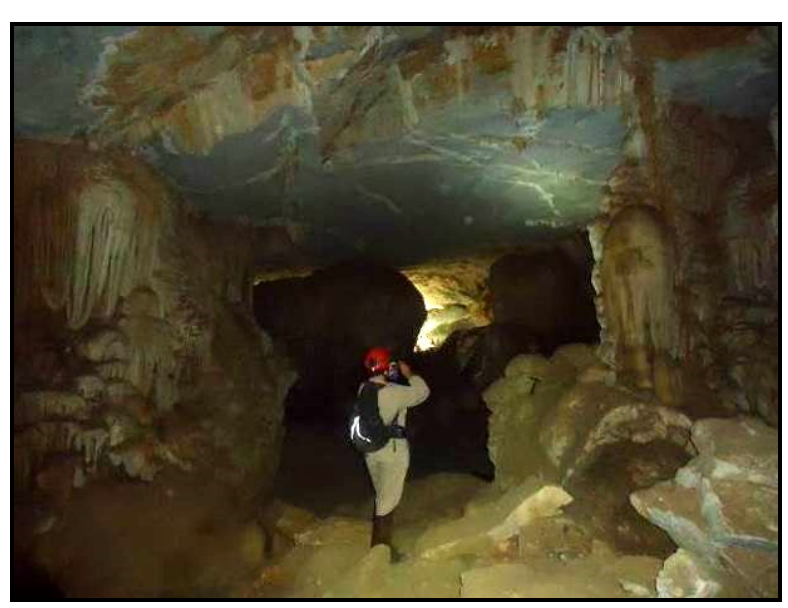

Figura 13 - Salão de entrada da Gruta do Brega, Pains (MG). Fonte: Mariana Barbosa Timo, 2013. 


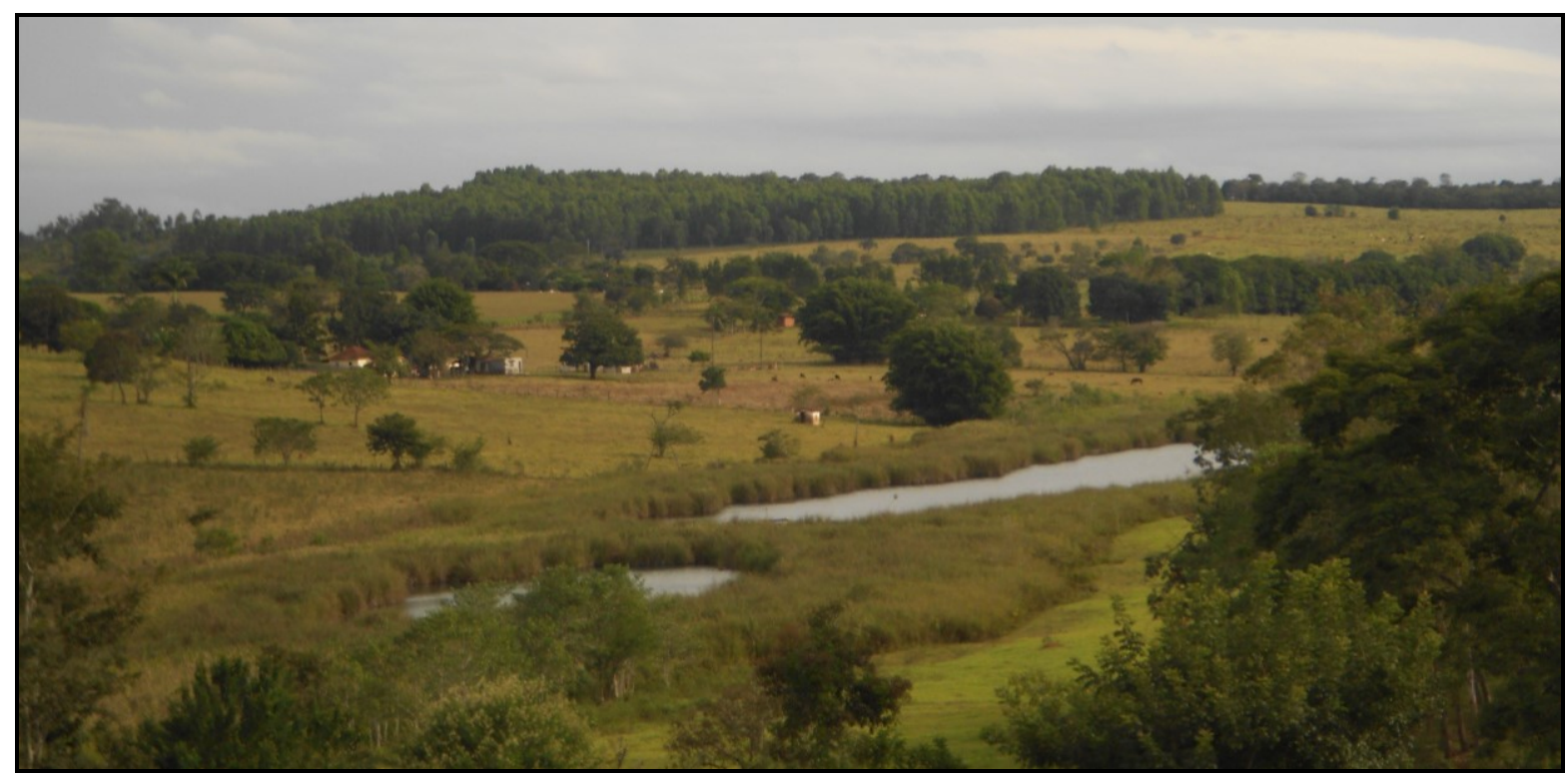

Figura 14 - Vista geral da lagoa cárstica conhecida como Lagoa dos Martins, Piumhí (MG). Fonte: Mariana Barbosa Timo, 2013.

\section{Planalto Cárstico do São Francisco (Bloco São Francisco)}

É constituído por dois tipos de calcários, às margens do rio São Francisco:

- Faixa Cânion do São Francisco: Os calcários apresentam-se contínuos e deformados, constituindo o cânion deste rio $(2,5 \mathrm{Km}$ à sudoeste da cidade de Doresópolis). Destaca-se um alinhamento de dolinas em sentido N-S nas proximidades do cânion;

- Faixa Arraial Novo: é caracterizada por maciços isolados, localizados principalmente, na margem esquerda do rio (a nordeste da localidade de Arraial Novo), sendo as rochas desta unidade fortemente tectonizadas.

A feição cárstica mais representativa desta Unidade Geomorfológica é o Cânion do São Francisco (Figura 15) que foi esculpido na rocha chegando a medir aproximadamente 80 metros de altura em alguns pontos. Podem ser observadas ainda dolinas, uvalas, vales cegos e afloramentos calcários. 


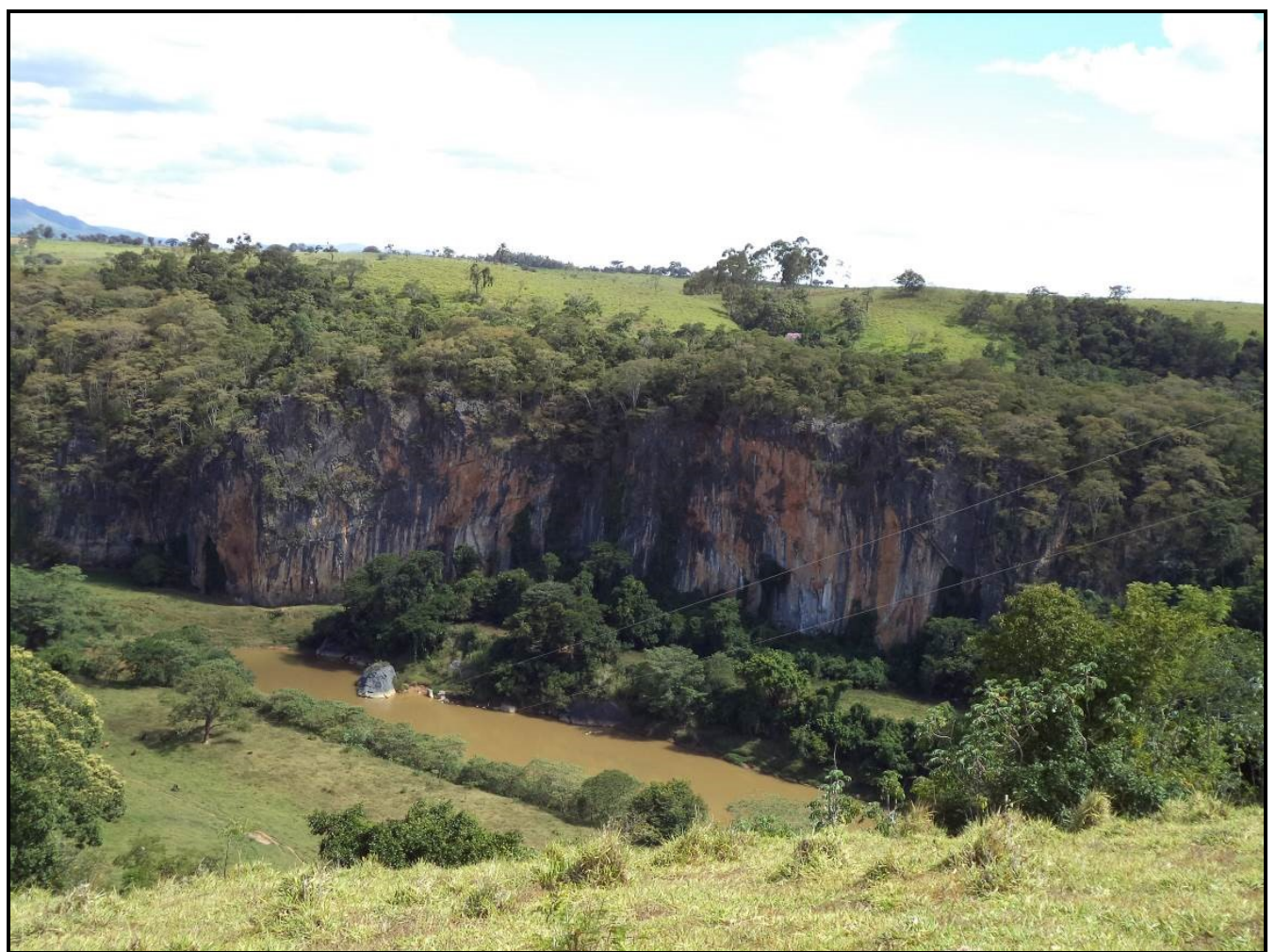

Figura 15 - Cânion do rio São Francisco, Doresópolis, MG.

Fonte: Mariana Barbosa Timo, 2014

\section{CONSIDERAÇÕES FINAIS}

$\mathrm{Na}$ Região Cárstica Arcos-Pains, as atividades humanas podem impor profundas modificações na paisagem, especialmente por causa da mineração, visto que ali encontram-se instaladas diversas empresas de extração de calcário, além de indústrias cimenteiras e de produção de cal. Tal uso do solo, aliado à precária gestão do Patrimônio Espeleológico, vem ocasionado impactos ambientais significativos no carste regional. Dessa forma, ter como base os estudos do carste faz-se extremamente necessário, pois a sensibilidade dos aquíferos cársticos à poluição é muito alta.

O carste desta região é um expressivo exemplo do carste intertropical brasileiro, por suas características geológicas, geomorfológicas, hidrológicas e arqueológicas. Sua evolução superficial e subterrânea deve, portanto, ser compreendida como um fenômeno complexo.

É importante se estabelecer parcerias para o aprofundamento das pesquisas envolvendo o entendimento da dinâmica dos processos cársticos e geomorfológicos 
da região. Tais levantamentos promoverão um maior conhecimento do patrimônio espeleológico nacional para orientar a tomada de decisões estratégicas.

\section{REFERÊNCIAS}

AGÊNCIA NACIONAL DE ÁGUAS - ANA. Disponível em: http://www2.ana.gov.br /Paginas/portais/bacias/SaoFrancisco.aspx Acesso em: 15 nov. 2013.

ALKMIN, F. F.; MARTINS-NETO, M. A. A Bacia Intracratônica do São Francisco: arcabouço estrutural e cenários evolutivos. In: PINTO, C. P.; MARTINS-NETO, M. A. (Ed.), Bacia do São Francisco: Geologia e Recursos Naturais. Belo Horizonte: SBG-MG, 2001, p. 9-30.

AULER, A.; RUBBIOLI, E. L.; BRANDI, R. As grandes cavernas do Brasil. Belo Horizonte: Rona Editora, v. 1, 2001. 230 p.

BAPTISTA, M. C.; SILVA, S. F. S.; DANTAS, M. E.; DUARTE, K. S.; ALMEIDA, B. F.; MURICY FILHO, A. F.; COUTINHO, C. I.; PEDROSA, L. Aspectos Gerais do Meio Físico. In: MACHADO, M. F.; SILVA, S. F. (Org.), Geodiversidade do estado de Minas Gerais. Belo Horizonte: CPRM, 2010, Cap. 2, p. 17-34. Disponível em: http://www.cprm.gov.br/publique/media/Geodiversidade MG.pdf. Acesso em 27 abr. 2014

BARBOSA, G. V. Notícia sobre o karst na Mata de Pains. Boletim Mineiro de Geografia, Belo Horizonte, n. 2 e 3, Ano II, p. 3-21, 1961.

BRASIL. Deccreto Federal $n^{\circ} 6.640$ de 07 de novembro de 2008. Dá nova redação aos arts. 1ㅇ, 2으, 3으, 4으 e 5으 e acrescenta os arts. 5-A e 5-B ao Decreto no 99.556, de 10 de outubro de 1990, que dispõe sobre a proteção das cavidades naturais subterrâneas existentes no território nacional. Ministério do Meio Ambiente, Brasília, 07 nov. 2008.

BRASIL. Instrução Normativa $\mathrm{n}^{\circ} 02$ de 20 de agosto de 2009. Estabelece a metodologia para a classificação da relevância das cavidades naturais subterrâneas e dá outras providências. Ministério do Meio Ambiente, Brasília, 21 ago. 2009.

BUENO, O.; TRAVASSOS, L.E.P. As Escalas da Geografia. Texto distribuído durante as aulas da disciplina Evolução do Pensamento Geográfico. 2012

CECAV - Centro Nacional de Pesquisa e Conservação de Cavernas. Base digital de dados geoespacializados de cavernas do Brasil, 2011. Instituto Chico Mendes. Disponível em: http://www.icmbio.gov.br/cecav/projetos-e-atividades/ provincias-espeleologicas.html. Acesso em 07 abr. 2013. 
CETEC - FUNDAÇÃO CENTRO TECNOLÓGICO DE MINAS GERAIS. Diagnóstico Ambiental do Estado de Minas Gerais, 1983. Fundação Centro Tecnológico de Minas Gerais/CETEC. Série de Publicações Técnicas/SPT-010. 158p.

CPRM - COMPANHIA DE PESQUISA E RECURSOS MINERAIS. Mapa Geológico do Brasil, 2003. Escala 1:2.500.000. CD-ROM.

CPRM - COMPANHIA DE PESQUISA E RECURSOS MINERAIS. Piumhi- SF.23-VB-II, escala 1:100.000: nota explicativa./André Ribeiro, Fábio Vito Pentagna Paciullo, Aracy Souza Senra, Cláudio de Morrison Valeriano, Rudolph Allard Jonnhanes Trouw - Minas Gerais: UFRJ/CPRM, 2007.

DARDENNE, M. A. Síntese sobre a estratigrafia do Grupo Bambuí no Brasil Central. In: SBG, XXX Congresso Brasileiro de Geologia, Recife, Anais, 2:597-610, 1978.

DARDENNE, M. A.; SCHOBBENHAUS, C. The Metallogenesis of the South American Platform. In: CORDANI, U. G.; MILANI, E. G.; THOMAZ-FILHO, A.; CAMPOS, D. A. (Ed.), Tectonic evolution of South America, p. 800-809, 2000.

DOMINGUEZ, J.M.L. 1993. As coberturas do Cráton do São Francisco: uma abordagem do ponto de vista da análise de bacias. In: DOMINGUEZ, J.M.L. ; MISI, A. eds. O Cráton do São Francisco. Salvador, SBG. p. 137-159

FÉLIX, A., A. ; FREITAS JÚNIOR, R. L. de. Mapeamento Geológico e Hidrogeológico da Bacia Hidrográfica do Rio São Miguel, Alto São Francisco, Estado de Minas Gerais. Trabalho de Graduação, IGC - UFMG, 2000.

HADDAD, Eduardo Abjaud. Influência Antrópica na Qualidade da Água da Bacia Hidrográfica do rio São Miguel, Carste do Alto São Francisco, Minas Gerais. 2012. 156f. Dissertação (Mestrado) - Universidade Federal de Minas Gerais, Departamento de Geografia, Belo Horizonte. Disponível em: http://www.bibliotecadigital.ufmg.br/dspace/bitstream/handle/1843/MPBB-

7LBML5/disserta o eduardo haddad. pdf;jsessionid=171A9F40106C8951EE926E0 5A86EF812?sequence=1. Acesso em 10 jun. 2013.

HARDT, Rubens. Aspectos da Geomorfologia Cárstica da Serra do Calcário, Cocalinho - MT. 2004. 98f. Dissertação (Mestrado) - Universidade Estadual Paulista, Instituto de Geociências e Ciências Exatas, Rio Claro. Disponível em: < http://pt.scribd.com/doc/51706241/HardtR-Dissertacao-2004> Acesso em 15 set. 2012.

IBGE - INSTITUTO BRASILEIRO DE GEOGRAFIA E ESTATÍSTICA. Carta Topográfica da Folha Piumhi (SF.23-V-D-II) escala 1:50.000: IBGE 1970. Belo Horizonte: IBGE, 1970.

IBGE - INSTITUTO BRASILEIRO DE GEOGRAFIA E ESTATÍSTICA. Mapas de biomas do Brasil: escala 1:5.000.000: IBGE 2004. Belo Horizonte: IBGE, 2004. Disponível em: http://mapas.ibge.gov/biomas2/viewer.htm. Acesso em 07 fev. 2013. 
IBGE - INSTITUTO BRASILEIRO DE GEOGRAFIA E ESTATÍSTICA. Estado de Minas Gerais: mesorregiões: IBGE 2012. Belo Horizonte: IBGE, 2012.

INSTITUTO NACIONAL DE METEREOLOGIA (INMET). Disponível em: http://www. inmet.gov.br/portal/index.php?r=home/page\&page=rede estacoes conv graf Acesso em 20 jan. 2013.

JANSEN, D.C; CAVALCANTI, L. F. LAMBLÉM, H. S. Mapa de Potencialidade de Ocorrência de Cavernas no Brasil, na escala 1:2.500.000. Revista Brasileira de Espeleologia, Brasília, v. 2, n.1, p. 42-57, 2012.

KARMANN, Ivo; SÁNCHEZ, Luis Enrique. Distribuição das rochas carbonáticas e províncias espeleológicas do Brasil. Revista Espeleotema, Monte Sião, v. 13, p. 105-167. 1979.

KARMANN, Ivo; SÁNCHEZ, Luis Enrique. Speleological provinces in Brazil. In: INTERNATIONAL CONGRESS OF SPELEOLOGY, 9, 1986, Barcelona. Anais... Barcelona: International Union of Speleology (UIS). 1986. v.1, p. 151-153.

KARMMAN, Ivo. Evolução Dinâmica Atual do Sistema Cárstico do Alto Vale do Ribeira de Iguape, Sudeste do Estado de São Paulo. 1994. 228f. Tese (Doutorado) - Universidade de São Paulo, Instituto de Geociências, São Paulo

KAUFMAN, G. Karst Landscape Evolution. Speleogenesis and Evolution of Karst Aquifers, v. 1, n. 3, p.2. Re-published by permission from: GABROVŠEK, F. (Ed.). 2002. Evolution of karst: from prekarst to cessation. Postojna-Ljubljana: Zalozba ZRC, 2003. p. 243-258.

KOHLER, H.C. Geomorfologia cárstica na região de Lagoa Santa. 1989. 113p. Tese (Doutorado) - Universidade de São Paulo

MADALOSSO, A.; VERONESE V. A. Considerações sobre a estratigrafia das rochas carbonáticas do Grupo Bambuí na região de Arcos, Pains e Lagoa da Prata. Anais do XXX Congresso Brasileiro de Geologia, Recife, 1978, v2 :635- 642, 1978.

MAPEAR LTDA. Estudo de Impacto Ambiental da Mineração Arcos Ltda., Fazenda Cupins, Zona Rural, Arcos, MG. 2003

MARTINS, Thallita Isabela Silva. Mapeamento Geomofológico da Folha Piumhi, Minas Gerais. 2013. 157f. Dissertação (Mestrado) - Universidade Federal de Uberlândia, Programa de Pós-Graduação em Geografia do Instituto de Geografia, Uberlândia. Disponível em: <http://www.bdtd.ufu.br/tde busca/arquivo.php?cod Arquivo=4856>. Acesso em 21 ago. 2013. 
MARTINS NETO, M. A.; PINTO, C. P. A Bacia do São Francisco: definição e base de dados. In: PINTO, C. P.; MARTINS-NETO, M. A. (Ed.), Bacia do São Francisco: Geologia e Recursos Naturais. Belo Horizonte: SBG-MG, 2001. p. 1-30.

MUZZI MAGALHÃES P., CHEMALE Jr. F. ; ALKMIM F.F. 1989. Estilo tectônico da porção sudoeste da Bacia do São Francisco. In: SBG/MG, Simp. Geol. Minas Gerais, 5, Belo Horizonte, Anais, p. 284-288. (Boletim 10).

MYERS, N.; MITTERMEIER, R. A.; MITTERMEIER, C. G.; FONSECA, G. A. B.; KENT, J. 2000. Biodiversity hotspots for conservation priorities. Nature 403: 853858.

OLIVEIRA, O. B.; OLIVITO, J. P.; RODRIGUES-SILVA, D. Caracterização da Unidade Espelológica e das Unidades Geomorfológicas da Região do Quadrilatéro Ferrífero - MG, Revista Espeleo-Tema, Brasília, v.22, n.1, p. 61-80, 2011.

Patrimônio Arqueológico. Disponível em: http://www.almg.gov.br/opencms/ export/sites/default/consulte/publicacoes assembleia/obras referencia/arquivos/pdfs Isao francisco/arqueologico.pdf. Acesso em 07 abr. 2013

PILÓ, Luís B. Ambientes Cársticos de Minas Gerais: valor, fragilidade e impactos ambientais decorrentes da atividade humana. Revista O Carste, Belo Horzonte, v. 11, n. 3, p. 50-58, 1999.

PIZARRO A P. Compartimentação Geológica Geomorfológica da Província Carbonática e Espeleológica de Arcos-Pains-Doresópolis. XL Congresso Brasileiro de Geologia -BH - SBG, 1998.

RODRIGUES, Bruno Durão. Identificação e mapeamento das matas secas associadas ao carste carbonático de Santo Hipólito e Monjolos, Minas Gerais. 2011. 106f. Dissertação (Mestrado) - Pontifícia Universidade Católica de Minas Gerais, Programa de Pós-Graduação em Geografia e Tratamento da Informação Espacial, Belo Horizonte. Disponível em: http://www.biblioteca.pucminas.br/teses/ TratInfEspacial RodriguesBD 1.pdf. Acesso em 03 jan. 2014.

ROLFF, P. A. M. A. Calcários de Arcos, Minas Gerais. Revista da Escola de Minas, Ouro Preto, v. 18, n. 4. 1953

ROLDAN, Luiz F.; WAHNFRIED, Ingo. D.; KLEIN, Daniel A. Breve Abordagem Geológica das Províncias Espeleológicas do Brasil. 2004. Disponível em: http://www.redespeleo.org/artigodet.asp?txtid=77. Acesso em: 06 abr. 2013

SANTOS, C. I. F. As relações entre o endocarste e exocarste na Província Cárstica de Arcos-Pains-Doresópolis/MG. 2002. 72f. Dissertação (Mestrado) Universidade Federal de Minas Gerais, 2002. 
SEE - SOCIEDADE EXCURCIONISTA E ESPELEOLÓGICA. Projeto Arcos Pains Espeleologia (PROAPE): SEE/DEGEO/EM/UFOP 2012. Ouro Preto: PROAPE, 2012.

SUPRAM - SUPERINTENDÊNCIA REGIONAL DE MEIO AMBIENTE E DESENVOLVIMENTO SUSTENTÁVEL. Parecer Único n 1861763/2013 - Minas Gerais: SUPRAM, 2013. (arquivo: Item_8.2_-_PU_-_Estrada_Bambui_-_Piumhi__DER-MG.pdf, na pasta Geologia).

TEIXEIRA, Paulo S. D.; DIAS Marcelo S. Levantamento espeleológico da região cárstica de Arcos, Pains, Doresópolis, Córrego Fundo e Iguatama, frente às atividades degradadoras. In: CONGRESSO BRASILEIRO DE ESPELEOLOGIA, 27, 2003, Minas Gerais. Anais:... Minas Gerais: Sociedade Brasileira de Espeleologia, 2003. p. 193-199. Disponível em: http://www.sbe.com.br/anais27 cbe/27cbe 193-199.pdf. Acessado em: 06 abr. 2013.

TIMO, M. B. Mapeamento geomorfológico da região Cárstica do Córrego do Cavalo, Piumhi (MG). 2014. 133f. Dissertação (Mestrado) - Pontifícia Universidade Católica de Minas Gerais, Programa de Pós-Graduação em Geografia e Tratamento da Informação Espacial, Belo Horizonte. Disponível em http://www.biblioteca .pucminas.br/teses/TratInfEspacial TimoMB 1.pdf. Acesso em 02 mar. 2017.

TRICART, J. O karst das vizinhanças setentrionais de Belo Horizonte. Revista Brasileira de Geografia, v. 18, n. 4. 1956. 